\title{
Olive oil as xylene substitute
}

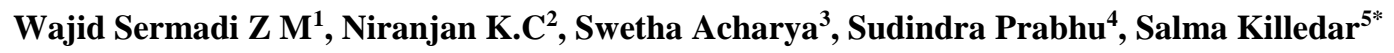 \\ ${ }^{1,5}$ Assistant Professor, ${ }^{2,3}$ Associate Professor, ${ }^{4}$ Professor, ${ }^{1}$ Chamrajnagar Institute of Medical Sciences, Chamrajnagar, Karnataka, ${ }^{2,3}$ SDM \\ College of Dental Sciences and Hospital, Dharwad, Karnataka, ${ }^{4}$ Yenepoya Dental College and Hospital, Mangalore, Karnataka, ${ }^{5}$ Karnataka \\ Institute of Medical Sciences, Hubli, Karnataka, India
}

*Corresponding Author: Salma Killedar

Email: zainul.wajid@gmail.com

\begin{abstract}
Introduction: Clearing agents are among the most noxious and hazardous chemicals found in the histology laboratories. Therefore in an effort to improve working conditions in the histopathology laboratory, we have investigated whether non-toxic substances may be substituted for the toxic organic solvent xylene currently in use.

Materials and Methods: Two tissue blocks from each 60 soft tissue specimen (anatomical structures in head and neck region) were subjected to parallel processing in xylene and olive oil. All the sections were stained with hematoxylin-eosin to permit evaluation of histologic details by two different observers. The collected data was subjected to statistical analysis using Wilcoxon matched pair test \& Mann-Whitney u test.

Results: The results showed no significant differences between the two different clearing agents in terms of gross tissue changes except for rigidity after clearing. Statistically significant gross tissue shrinkage evident in xylene was not seen in vegetable oil processed tissue. The cellular details were well preserved and the staining intensity was uniform. In the histochemical and immunohistochemical staining, no differences were registered. Morphometrically there was significant difference in mean area of epithelial (parabasal) cells and mucous acini in xylene processed tissues compared to that of olive oil.

Conclusion: The overall results have demonstrated professional acceptance of olive oil as a substitute for xylene, without losing valuable diagnostic information.
\end{abstract}

Keywords: Clearing agents, Xylene, Olive Oil, Histopathology, Immunohistochemistry.

\section{Introduction}

Clearing agents are among the most noxious and hazardous chemicals found in histology laboratories. Toxic effects of xylene includes acute neurotoxicity, cardiac and kidney injuries, some fatal blood dyscrasias, and other less dangerous problems, such as skin erythema, drying and scaling, and secondary infections, all associated with its use and caused by depletion of mitochondrial adenosine triphosphate in the affected cells. Because of new regulations from Occupational Safety and Health Administration (OSHA) and the Environmental Protection Agency (EPA), ${ }^{1-9}$ several xylene substitutes such as limonene reagents, aliphatic hydrocarbons, vegetable oils and mineral oils have been commercially developed in recent years. ${ }^{10-13}$ However these commercially available xylene substitutes are less effective, more expensive, and not much less hazardous than xylene itself. Coconut and olive oil are commonly used vegetable oils available throughout the tropical world. They are non-toxic, heat stable, slow to oxidize and have highest resistant to rancidity. ${ }^{14-16}$ Therefore in an effort to improve working conditions in the histopathology laboratory, we intend to use non-bio hazardous substitute like olive oil that does not compromise the staining quality but will also preserve the cellular and nuclear morphology and are economical as well.

\section{Materials and Methods}

60 different formalin fixed tissue types (skin, oral mucosa, salivary gland, tendon, muscle, lymph node) from redundant tissue obtained during minor and major (RND) oral surgical procedures were subjected to parallel processing (clearing) in xylene and olive oil (Fig. 1). Only soft tissue was preferred for this study. The specimen size was $0.5 \times 1 \mathrm{~cm}$ or greater and a tissue thickness of 3-5 mm was taken for processing (for better penetration of the processing fluids).

Features such as translucency, rigidity, degree of shrinkage, procedures like impregnation \& microtomy were compared to that of xylene with olive oil processed tissue blocks. All the sections were stained with hematoxylineosin to permit evaluation of histologic details by two different observers.

Sections from 10 tissue samples were stained with special and immunohistochemical stains. Special stain such periodic acid Schiff (PAS) and Toulidine blue were used. Immunohistochemical analysis was performed using primary mouse monoclonal antibody Cluster of differentiation 34 (CD34) and visualized by supersensitive polymer- Horse radish peroxidase (HRP) detection system [BIOGENEX, San Ramon, California, USA], chromogen DAB (diamino benzidine) was used. The histochemical and immunohistochemical staining results were evaluated for the pattern and the intensity of reactions.

\section{Criteria for Evaluation}

\section{Gross tissue changes after clearing}

1. After clearing in two different de-alcoholisation agents like xylene and olive oil, gross tissue features such as: -

2. Translucency (surface translucency when viewed with reflected light),

3. Rigidity (palpation with two fingers) 
4. Change after impregnation (change in the rigidity because of infiltration of wax)

5. Ease in section cutting were noted down for each specimen separately.

6. Scoring was done while comparing the parameter for both xylene and its substitute. If the findings of substitute found to be inferior to xylene it was considered as score 0 , similar to xylene as score 1 and superior to xylene as score 2 .

\section{Gross Tissue Shrinkage}

Metric measurements were recorded before and after clearing to compare the gross shrinkage between the solvents (Fig. 2).

\section{Staining Criteria}

The stained slides in each group processed by xylene and its substitute were coded with alphabet A and B. Two observers evaluated all slides without the knowledge of the type of clearant used.

\section{Cytoplasmic Details}

For cytoplasmic details, distinct architecture and good nuclear-cytoplasmic contrast was considered as score 1 and indistinct / blurred nuclear-cytoplasmic contrast as score 0 .

\section{Nuclear Details}

For nuclear details, distinct chromatin condensation, prominent nuclear membrane and crisp staining of nucleus as score 1 and indinstinct smudging and pyknosis of nuclei as score 0 .

\section{Quality of Staining}

Staining of tissues was evaluated as poor, satisfactory and good. Poor indicates that the tissue failed to take up stain adequately, stained unevenly $($ score $=0)$. Satisfactory indicates details not visualized up to the mark (score $=1$ ). Good designates good contrast between the nucleus and cytoplasm and visibility of details along with brilliance of staining (score $=2$ ).

\section{Histochemical and Immunohistochemical Staining}

For the histochemical and immunohistochemical sections, poor indicates non specific reaction $($ score $=0)$. Satisfactory indicates reaction specificity (score $=1$ ). Good designates reaction intensity and reaction specificity $($ score $=2)$.

\section{Morphometric Analysis}

Histologically identifiable mucous acini from the lobules of minor salivary gland and selected fields for parabasal layer of oral epithelium were subjected for measurement. Images of the cells under $40 \times$ objective magnifications were captured and subjected to morphometric analysis. Totally 100 cells randomly selected and measured for any difference in xylene specimens and vegetable oil specimens. The images were classified, transferred and stored in the computer. The actual measurements of the morphometric parameters were done using the image analyzer software Leica Qwin Plus version 3. Cell area was measured in square microns. The mean area of mucous acini and parabasal cells was then evaluated for each sample and subjected to statistical analysis (Fig. 3).

Since most of the evaluative criteria were subjective, the scoring and assessment was carried out by two different observers and mean scoring was considered which will prevent inter-observer bias. The obtained data was subjected to statistical analysis using Mann-Whitney $U$ test \& Wilcoxon matched pair test. A significance level of $p<0.05$ was used for all tests and comparisons.
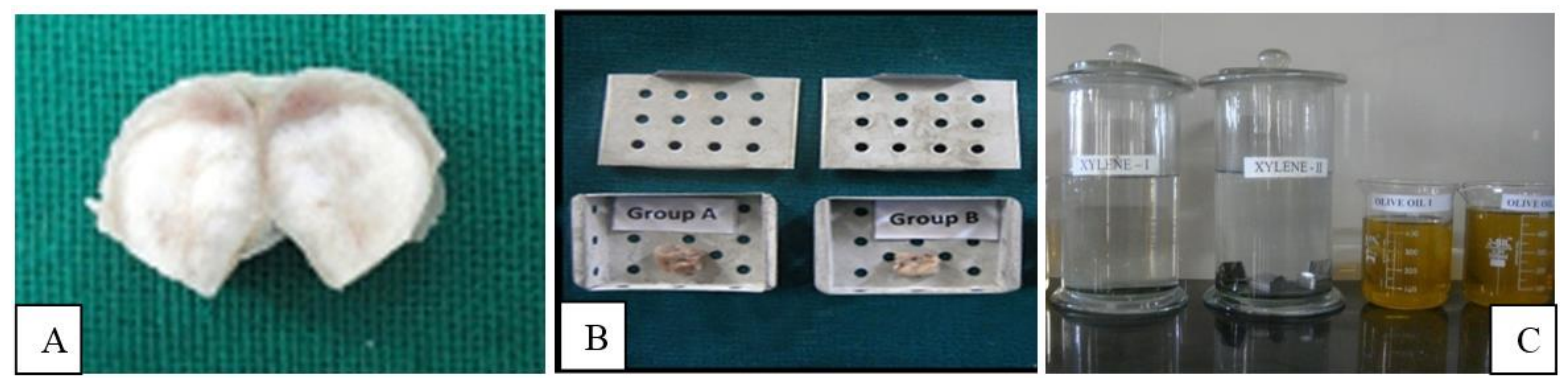

Fig. 1(A,B \& C): Tissue specimen divided in to 2 bits. Parallel processing in xylene and olive oil

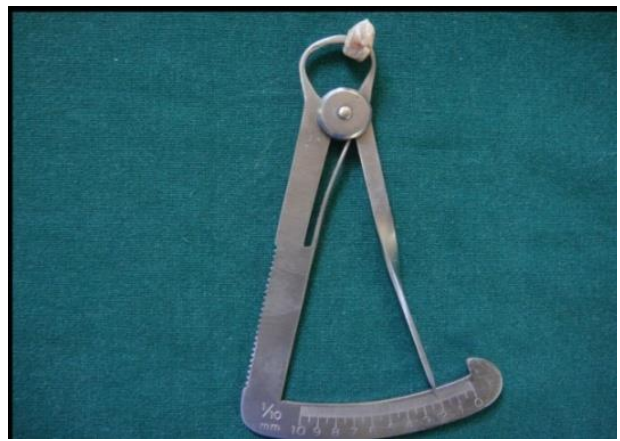

Fig. 2: Metric measurement of tissue samples. 

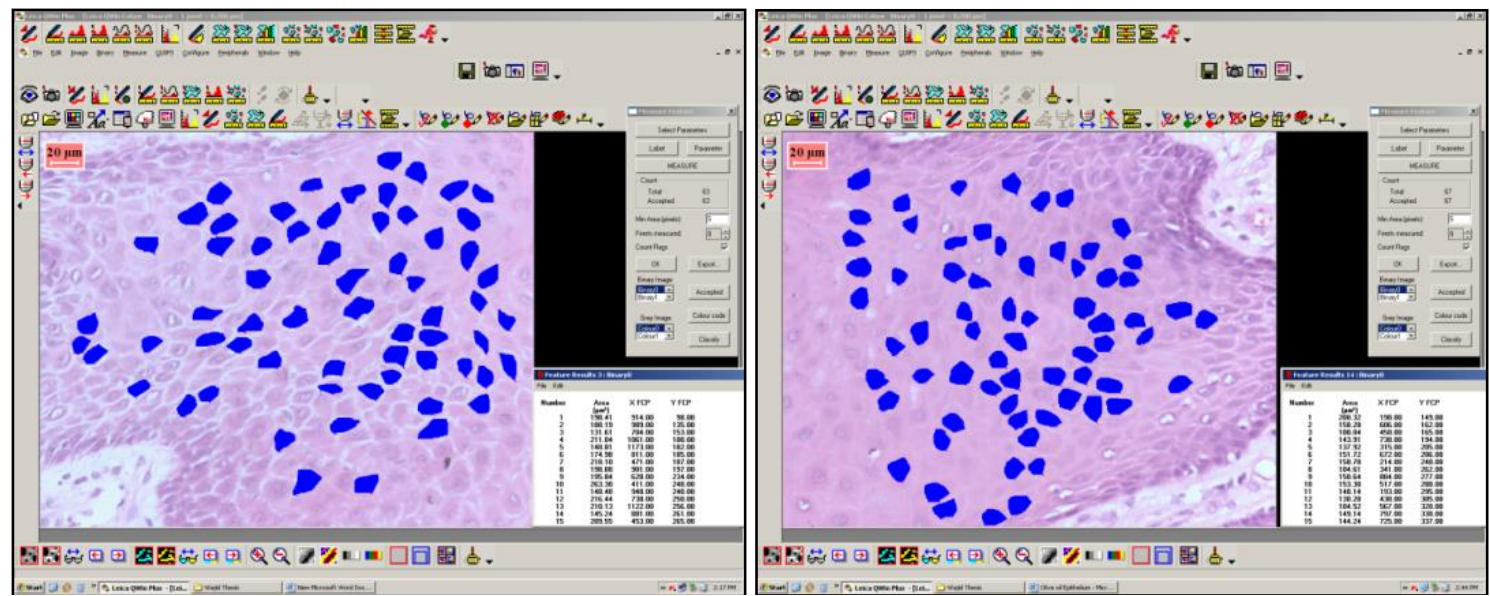

Fig. 3: Morphometric analysis of mean area of individual parabasal cells to assess shrinkage at the cellular level (original magnification: $\mathrm{x}$ 40)

\section{Results}

Gross tissue changes such as translucency, impregnation, rigidity and ease of sectioning were found to be having score of 1 in all samples (100\%). where as in rigidity after clearing, $61.70 \%$ of olive oil processed sample showed score of 0 , suggesting less rigid than xylene and the remaining $38.30 \%$ of samples had same rigidity as that of xylene with score 1 (Graph 1).

All tissue samples processed in olive oil had a score of $1(100 \%)$ for cytoplasm and nuclear details indicating distinct cytoplasmic and nuclear features (Fig. 4). Quality of staining was graded good to $95 \%$ (olive oil). Histochemical and immunohistochemical stains showed identical features in both xylene and olive oil processed samples (Graph 2). Periodic acid Schiff's reagent when used on submandibular gland stained mucous cells with magenta color indicating same stain intensity and specificity as that of xylene processed tissue samples (Fig. 5). Mast cells were visualized using Toluidine blue stain (Fig. 6). Immunohistochemistry performed using monoclonal antibody Cluster of differentiation 34 CD34 showed specific staining towards endothelial cell lined capillaries (Fig. 7). The oil cleared specimens showed neither false-negative nor false positive staining and enhanced nonspecific background was not found in the immunohistochemical investigations.

Gross tissue shrinkage by metric measurement, prior to and after clearing in xylene using paired sample test, shows difference in volume of the tissue before and after clearing in xylene (Graph $3 \&$ Table 1).Statistical significant result was obtained $(\mathrm{p}-<0.0000)$.

Morphometrically, there was a significant decrease in the mean area of the individual cells in xylene processed sample, compared to olive oil sample $(p=0.011)$ (Table 2).

Graph 1: Percentage analysis of olive oil in comparison to xylene under the criteria of gross tissue shrinkage

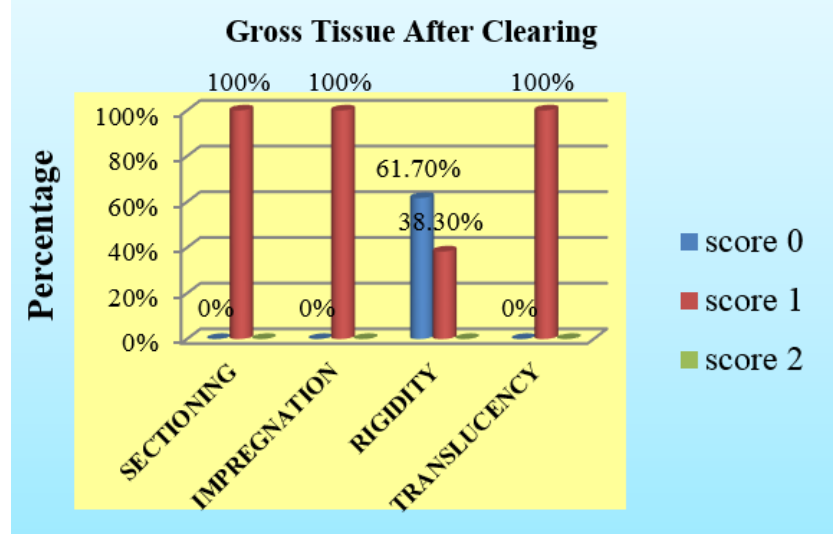

Graph 2: Percentage analysis of staining criteria

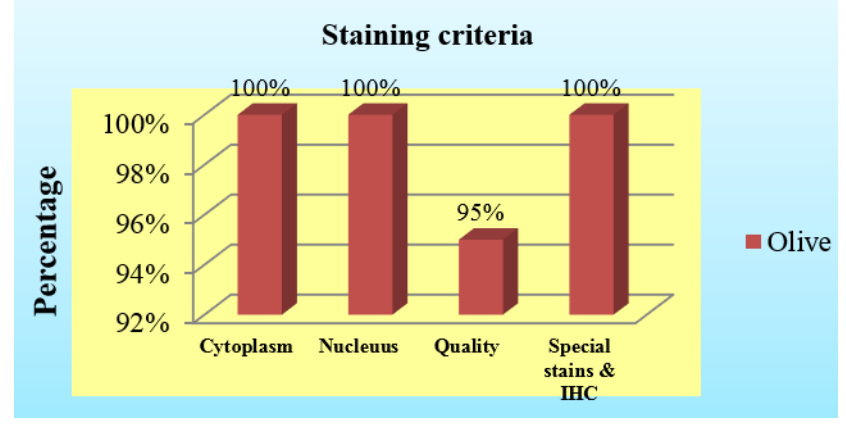

Graph 3: Metric measurement of gross tissue shrinkage

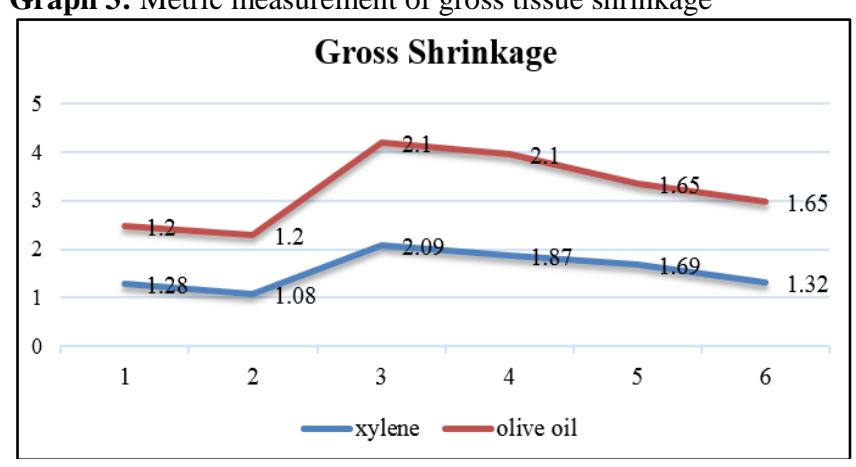


Table 1: Comparison of before and after values of area in Xylene and olive oil groups (Wilcoxon matched pairs test)

\begin{tabular}{|c|c|c|c|c|c|c|c|}
\hline & & Mean & Std.Dv. & Mean diff & SD diff & Z-value & P-value \\
\hline Xylene & Before & 1.2295 & 0.5446 & & & & \\
\hline & After & 1.1407 & 0.5512 & 0.0888 & 0.1344 & 4.5407 & $\mathbf{0 . 0 0 0 0}$ \\
\hline Olive Oil & Before & 1.2349 & 0.5492 & & & & \\
\hline & After & 1.2353 & 0.5511 & -0.0003 & 0.0722 & 0.7303 & 0.4652 \\
\hline
\end{tabular}

Table 2: Morphometric analysis of mean area in $\mu \mathrm{m}^{2}$ of 100 epithelial (parabasal) cells

\begin{tabular}{|c|c|c|c|}
\hline Groups & Mean \pm SD & f- value & p - value \\
\hline Parabasal cells & & & \\
Xylene & $168.54 \pm 45.17$ & & \\
Olive oil & $185.03 \pm 41.79$ & 5.419 & 0.011 \\
\hline
\end{tabular}
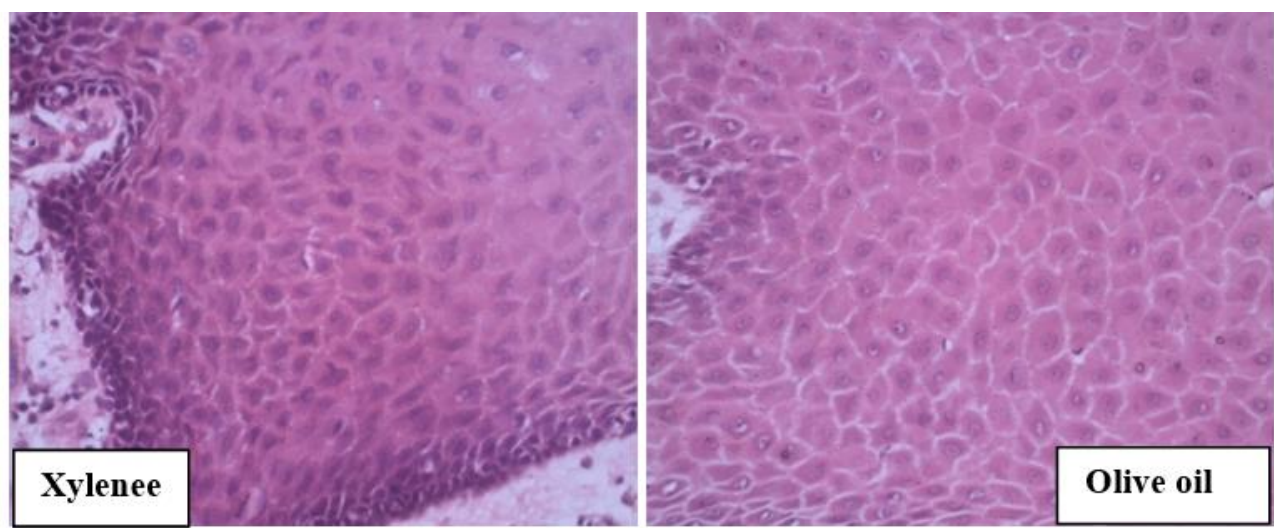

Fig. 4: Oral mucosa showing intercellular bridges, distinct nuclear cytoplasmic contrast and distinct nuclear boundaries (original magnification: $\mathrm{x} 40$ )

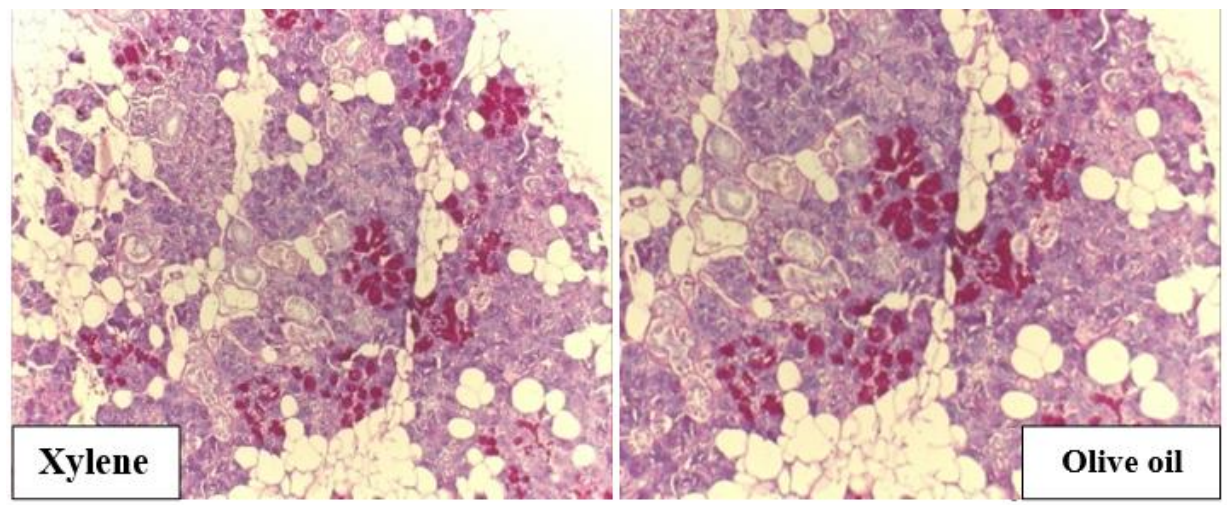

Fig. 5: Submandibular gland showing PAS positive mucous cells (original magnification: $x$ 10)

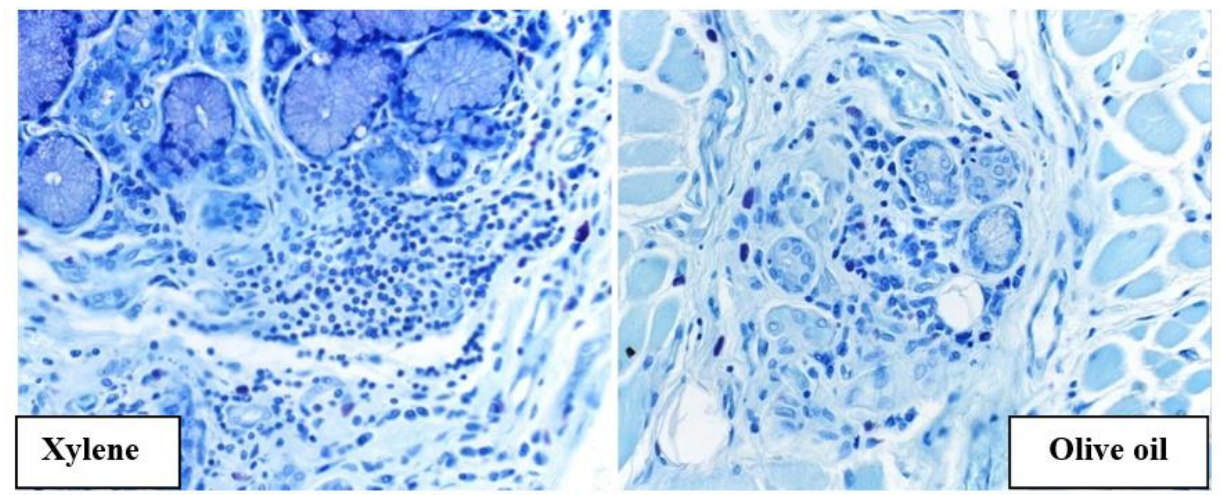

Fig. 6: Samples showing Toluidine blue positive mast cells (original magnification: $\mathrm{x} 40$ ) 


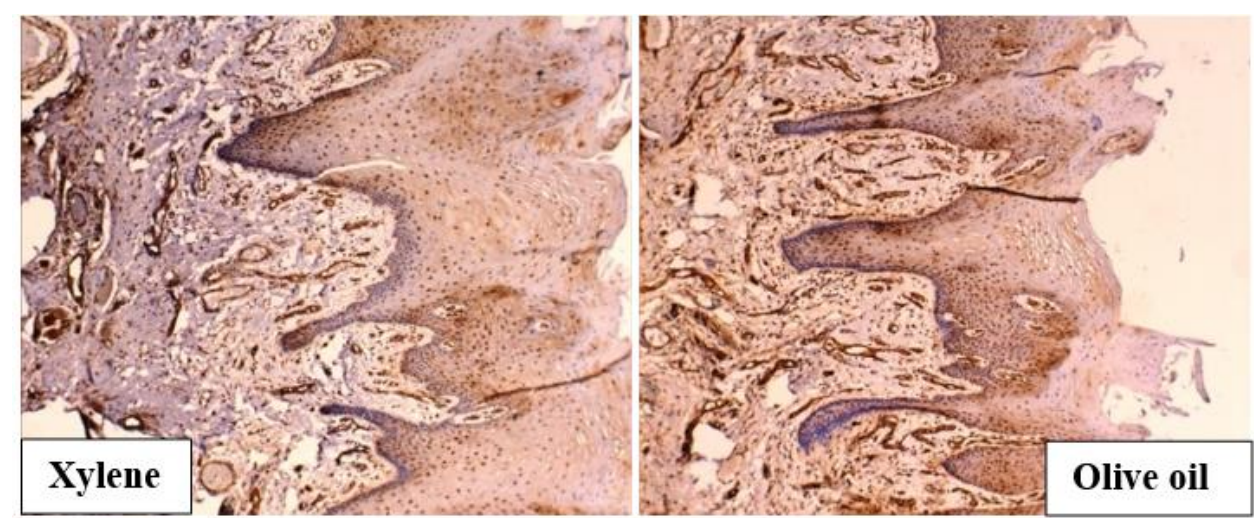

Fig. 7: Oral mucosa showing IHC (CD34) positive Blood capillaries (original magnification: x 10)

\section{Discussion}

The basis behind this study is from an environmental point of view, where it is highly desirable to substitute ecofriendly substance for xylene and produce histological sections equivalent to the conventional ones. Olive oil studied here is nontoxic to handle and disposal of the used oils demand no special procedure. Use of olive oil will not only ensure environmental and personal safety but also be cost effective.

This study is continuation of early study involving coconut oil as substitute, where as in this study we have used olive oil as substitute, including new parameter such as immunohistochemistry evaluation which till recent date has not been evaluated.

Caxton-Martins et al (1987) used Adi agbon, an oily extract of the endosperm of the coconut fruit (Cocoa nucifera, L.) and investigated it as a clearing agent for embryonic soft tissues. Paraffin sections stained with hematoxylin and eosin revealed normal tissue architecture and light microscopic details were easily visualized, ${ }^{17}$ while Rasmussen et al (1992) studied five different vegetable oils and recommended olive oil and coconut oil as xylene substitute in clearing and deparaffinisation procedure respectively. ${ }^{11}$ Grande and Phillips (1985) tested the commercially available vegetable oil derivative "HistoClear" and concluded that vegetable oil derivatives can be substituted for organic solvents without serious problems. ${ }^{11}$

Our investigation similarly suggests that in histological tissue preparations, vegetable oils may be effectively and advantageously substituted for xylene. Substitution yielded no significant reduction in quality. Moreover, this finding remains constant, regardless of tissue preparation procedure; whether the sections were stained with $\mathrm{H}$ and $\mathrm{E}$, special stains or subjected to immunohistochemical procedures. Histological details and quality was well maintained using oils. Use of this technique in parallel with the standard technique for several months confirmed the results reported herein.

However studies by Kimberley Edwards et al and Pritam Panja et al have highlighted on tissue shrinkage caused by xylene, ${ }^{19}$ and has substituted xylene with Acetonitrile and Microwave tissue processor but shrinkage was measured grossly and not morphometrically.
In the present study, shrinkage of the tissues was evaluated by metric measurement prior to and after clearing. Tissues processed in xylene showed statistical shrinkage before and after clearing $(\mathrm{p}=0.000)$ which was not reported in oil processed tissues. Epithelial cells from parabasal layer were assessed because of well delineated cellular boundaries and overcome the bias of overlapping cells in basal layer. Statistical significant difference in mean cell area between the groups ( $\mathrm{p}=0.011$ ) was observed.

Olive oil is non polar liquid which is miscible with alcohol (semipolar) \& paraffin wax (non polar). Olive oil with a density of $0.88 \mathrm{gm} / \mathrm{ml}$ is closer to the average density of human fat $(0.918 \mathrm{gm} / \mathrm{ml})^{20}$ which allows olive oil to eliminate fat by displacement, rather than dissolution as Xylene does. Therfore preserves cellular architecture \& eliminates tissue shrinkage.

The concern using vegetable oils as substitute for xylene is its high viscosity. The high oil viscosity could be attributed to the stronger attraction force between oil molecules. Liquid viscosities are sensitive to temperature. ${ }^{21}$ Therefore processing tissue samples in vegetable oils in a thermostatically controlled incubator at a temperature of $37^{\circ} \mathrm{C}$ facilitated easy diffusion into tissues causing clearing.

Although the oils are somewhat more expensive than xylene elsewhere in the world, these upfront costs are approximately negated by high disposal and recycling costs associated with the use of xylene.

\section{Conclusion}

It can be inferred from the present investigation that olive oil have no adverse effects on the quality of staining, cellular and nuclear details with absence of shrinkage during clearing as compared to xylene cleared tissue samples. However it is necessary to investigate a broader range of tissues including hard, decalcified tissues, tissues of different consistencies together (example: dentin and pulp) and various pathological diagnosis, to draw a definitive conclusions about the advantages of vegetable oils methods over conventional one.

\section{Conflict of Interest: None.}




\section{References}

1. Sermadi W, Prabhu S, Acharya S, Javali SB. Comparing the efficacy of coconut oil and xylene as a clearing agent in the histopathology laboratory. J Oral Maxillofac Pathol 2014;18 (Suppl 1):49-53.

2. Kandyala R, Raghavendra SP, Rajasekharan ST. Xylene: An overview of its health hazards and preventive measures. J Oral Max Pathol 2010;14:1-5.

3. Toxicological profile for xylene, U.S Department of Health and Human Services, public health service, Agency for toxic substance and disease registry. Atlanta: Georgia;1993.

4. Occupational safety and health administration-2005. Air contaminants, occupational safety and health administration. Available from: http://www.osha.gov[Last accessed on 2013 Jan 01].

5. National Institute for Occupational Safety and Health (NIOSH) criteria for a recommended standard: Occupational exposure to xylene 1975. Available from: http://www.cdc.gov/niosh/75168.html [last cited on 2012 Nov 16].

6. Langman, Jenifer. Xylene: Its toxicity, measurement of exposure levels, absorption, metabolism and clearance. Pathol 1994;26(3):301-9.

7. Engstrom K, Husman K, Pfaffli P, Riihimaki V. Evaluation of occupational exposure to xylene by blood, exhaled air and urine analysis. Scand J Work Environ Health 1978;4:114-21.

8. Buesa RJ, Maxim VP. Histology without xylene. Ann Diagn Pathol 2009;13:246-56.

9. Revilla AS, Pestana CR, Pardo-Andreu GL, Santos AC, Uyemura SA, Gonzales ME, et al. Potential toxicity of toluene and xylene evoked by mitochondrial uncoupling. Toxicol Vitro 2007;21:782-8.

10. Buesa RJ. Mineral oil: The best xylene substitute for tissue processing yet. J Histotechnol 2000;23:143-9.

11. Rasmussen B, Hjort K, Mellerup I, Sether G, Christensen N. Vegetable oils instead of xylene in tissue processing. Acta Pathol Microbio Immunol Scandinavica 1992;100:827-31.

12. Lyon H, Holm I, Prento P, Balslev E. Non-hazardous organic solvents in the paraffin embedding technique: A rational approach. Histochem Cell Biol 1995;103:263-9.
13. Andre GG, Wenger JB, Rebolloso D, Arrington JB, Mehm WJ Evaluation of clearing and infiltration mixtures (CIMs) as xylene substitutes for tissue processing. J Histotechnol 1994;17:137-42.

14. Kenan Tanılgana, Musa Özcanb K and Ünver A. Physical and chemical characteristics of five Turkish olive (Olea europea L.) varieties and their oils. Grasas y Aceites 2007;58(2):142-7.

15. Okoro L N, Sambo F I, Lawal M Nwaeburu C Thermodynamic and Viscometric Evaluation of Biodiesel and Blends from Olive Oil and Cashew Nut Oil. Res J Chem Sci 2011;1(4):90-7.

16. Waterman E, Lockwood B. Active Components and Clinical Applications of Olive Oil. Altern Med Rev 2007;12(4):331-42.

17. Caxton-Martins AE, Ehilegbu G, Uche-Nwachi EO, Agbe SA, Oluwadiya JO. Preliminary investigations into adi agbon as a clearing agent in routine histology. Stain Technol 1987;62(6):417.

18. Rasmussen BB, Hjort K N, Mellerup I, Sether G, Christensen N. Vegetable oils instead of xylene in tissue processing. Acta Pathol Microbio Immunol Scandinavica 1992;100(9):827-31.

19. Panja P, Sriram G, Saraswathi TR, Sivapathasundaram B. Comparison of three different methods of tissue processing. $J$ Oral Maxillofac Pathol 2007;11(1):15-7.

20. Shahidi F. Bailey's Industrial Oil and Fat Products. 6th ed. John Wiley \& Sons, Inc;. 2005: 303-31.

21. Goh Eng Giap S. The Hidden Property of Arrhenius-type Relationship: Viscosity as a Function of Temperature. J Phys Sci 2010;21(1):29-39.

How to cite this article: Sermadi WZM, Niranjan KC, Acharya S, Prabhu S, Killedar S. Olive oil as xylene substitute. J Oral Med, Oral Surg, Oral Pathol, Oral Radiol 2019;5(2):46-51. 